Western North American Naturalist 67(3), (C) 2007, pp. 378-383

\title{
DESERT RODENTS REDUCE SEEDLING RECRUITMENT OF SALSOLA PAULSENII
}

\author{
William S. Longland ${ }^{1}$
}

\begin{abstract}
Heteromyid rodents in the deserts of North America have been shown to harvest large quantities of seeds of both native and introduced plants from soil seed banks, but rarely has the impact of this seed removal been demonstrated experimentally. I used a series of fenced plots (some of which excluded rodents) to demonstrate that heteromyids at a western Nevada study site can measurably reduce seed banks and subsequent seedling establishment of Salsola paulsenii, an introduced invasive weed that has become a significant problem over much of the desert Southwest. The frequency of S. paulsenii seedlings in both 2004 and 2005 was significantly greater around the interior perimeters of plots that permitted access by rodents than in plots that excluded rodents. Density of S. paulsenii seedlings was significantly greater inside than outside rodent exclusion plots, but there was no such difference in seedling density inside versus outside plots that permitted rodent access. Salsola paulsenii has such a conspicuous presence in many desert environments that the effect of rodents in reducing its abundance may not be visually apparent; however, rodents may still ameliorate competitive effects of this weed on coexisting plants. Heteromyid rodents disperse seeds through caching, and they also consume them. Caching may enhance establishment of native plant seedlings, but is unlikely to benefit exotics such as S. paulsenii.
\end{abstract}

Key words: barbwire Russian thistle, Heteromyidae, seed bank, seedling establishment, postdispersal seed predation, Great Basin Desert, Nevada.

Rodent taxa of the North American deserts are largely granivorous, consuming and caching large quantities of seeds. Kangaroo rats (Dipodomys spp.) and other genera in the family Heteromyidae are perhaps the most specialized granivores in these deserts. Their suite of adaptations for a diet of seeds in an arid environment includes (1) extreme efficiency in locating buried seeds by olfaction (Johnson and Jorgensen 1981, Vander Wall et al. 2003); (2) ability to separate soil from and harvest clusters of seeds very rapidly (Price and Heinz 1984, Vander Wall et al. 1998); (3) external, fur-lined cheek pouches wherein they can carry large numbers of harvested seeds during their foraging activities; (4) 2 distinctly different caching behaviors, either larderhoarding (storage deep within a home burrow) or scatterhoarding (storage of groups of a few to several hundred seeds buried in shallow subsurface locations); and (5) strong spatial memory abilities which enable them to relocate hundreds of scatterhoard locations within their home ranges (Jacobs 1992). These features of individual heteromyids, along with high densities of single heteromyid species and diverse assem- blages of coexisting heteromyid species, can cause these animals to have a major influence on local desert plant communities. Their effects can be so profound that they have been characterized as keystone species in the deserts they inhabit (Brown and Heske 1990, Schiffman 1997).

Rodents, in general, are capable of consuming considerable proportions of the annual seed production of a plant species or group of plants (Reichman 1979, Price and Jenkins 1986, Longland 1994, Hulme 1998). In addition to the direct negative impacts of this seed predation on native plant species, disturbance of soil through rodent foraging activities can indirectly impact native plants by facilitating the establishment of competing exotic plants (Schiffman 1997). On the other hand, Brown and Heske (1990) showed that rodent activity, primarily by kangaroo rats, reduced densities of an introduced invasive grass species (Eragrostris lehmanniana) at a southern Arizona site. Moreover, some studies have quantified beneficial aspects of direct seed predation by rodents, such as the predation that occurs on weed species in agroecosystems (Getz and 
Brighty 1986, Harrison et al. 2003, Westerman et al. 2003). While they typically do not occur in intensively managed agroecosystems, heteromyids have been shown in 1 study to consume the majority of the annual seed crop of a rangeland weed species (Soholt 1973). In this study I used a series of fenced plots, some of which were rodent-proof, to test whether heteromyid rodents at a western Nevada site measurably reduced soil seed banks and subsequent seedling recruitment of a widespread invasive weed, barbwire Russian thistle (Salsola paulsenii).

Salsola paulsenii is an annual weed in the chenopod family that frequently invades sandy and limestone-derived soils in low-elevation $(<1250 \mathrm{~m})$ deserts of the western United States (Beatley 1973, Young and Evans 1979, Evans and Young 1980, Smith 2005). Salsola paulsenii has thick stems bearing small leaves with spiny tips, and generally has a rather short stature $(<50 \mathrm{~cm})$. This plant often hybridizes with a congener, S. tragus, another invasive weed that tends to occur at higher elevations and in less xeric conditions than S. paulsenii (Beatley 1973). Unlike S. tragus, which dislodges at the stem upon maturity and must roll in a classic tumbleweed fashion to disperse its seeds, seeds of S. paulsenii drop beneath the parent plant (Young and Evans 1979, Evans and Young 1980). At a site near the location of the current study, Evans and Young (1980) found that individual S. paulsenii plants usually produced $<1000$ seeds; in contrast, they reported that $S$. tragus individuals may produce up to 200,000 seeds. Seed mass in S. paulsenii varies considerably with plant density, with a reported range of approximately $30-90$ seeds $\cdot \mathrm{g}^{-1}$ (Evans and Young 1980).

\section{Methods}

The study was conducted on 15-16 March 2004 and 11-13 May 2005 at the Hot Spring Mountains in western Nevada (Lyon and Churchill Cos.; $\left.39^{\circ} 42^{\prime} 10^{\prime \prime} \mathrm{N}, 119^{\circ} 03^{\prime} 31.9^{\prime \prime} \mathrm{W}\right)$, a small basaltic range with a semistable covering of sand of variable depth on the lower slopes. The area is typified by sparsely distributed, salt-tolerant desert shrubs, such as Atriplex confertifolia, A. canescens, Kochia americana, Sarcobatus baileyi, Psorothamnus polydenius, Tetrademia spinosa, and T. tetrameres. Rodent species occurring at the Hot Springs Moun- tains are mainly heteromyids; typically, $40 \%-$ $70 \%$ of animals captured in live-traps were Merriam's kangaroo rat (Dipodomys merriami), with the vast majority of remaining captures made up of desert kangaroo rat (D. deserti), pallid kangaroo mouse (Microdipodops palli$d u s$ ), and little pocket mouse (Perognathus longimembris). The only nonheteromyid species that occurs with any regularity is the whitetailed antelope ground squirrel (Ammospermophilus leucurus).

The site has 30 plots, distributed in 3 blocks of 10 , with $>200 \mathrm{~m}$ between adjacent plots within a block and $>500 \mathrm{~m}$ between different blocks. Each plot is fenced with reinforced 0.6cm-mesh hardware cloth buried to a depth of approximately $0.5 \mathrm{~m}$. Most fences are still functional 10 years after they were constructed. Approximately half of those plots have fences completely intact to prevent entry by rodents (hereafter referred to as "no-rodent" plots), while the remaining plots have four $7.5 \times 7.5$ $\mathrm{cm}$ openings ( 1 per fence side) cut in the hardware cloth at the level of the soil surface, enabling rodents to enter and exit ("rodentaccess" plots). Each plot is square and measures $5 \times 5 \mathrm{~m}$. Further description of the plots and the study area is provided in Longland et al. (2001).

Viable S. paulsenii seeds germinate readily in response to moisture (Young and Evans 1979, Evans and Young 1980), so emergence of seedlings following precipitation that thoroughly wets the soil is an accurate reflection of seeds that were in soil seed banks. All sampling was conducted 7-15 days following a precipitation event that produced a visually apparent flush of S. paulsenii seedlings. I tested for effects of rodent access to plots on S. paulsenii seed banks in 2 ways. First, I compared the frequency of seedlings around the interior edges (where wind-blown seeds tend to accumulate) of rodent-access plots versus no-rodent plots. Each side of a fenced plot was divided into 25 contiguous segments of $20 \mathrm{~cm}$, and I searched for seedlings within $20 \mathrm{~cm}$ of the fence. Therefore, each side of a plot was considered as 25 contiguous $20 \times 20$-cm sampling quadrats. An entire plot thus yielded 96 such quadrats $(25$ per side $\times 4$ sides, 4 corner quadrats in common between adjoining sides). I counted the number of these quadrats in each plot that had any S. paulsenii seedlings. Second, I compared the number of $S$. paulsenii 
seedlings within four $0.25-\mathrm{m}^{2}$ (i.e., $0.5 \times 0.5$ $\mathrm{m})$ sampling frames placed randomly both inside and outside of each plot. The locations of both inside and outside samples were constrained to $>1 \mathrm{~m}$ from plot walls to prevent sampling of any seedlings emerging from seeds trapped by wind against plot fences. Outside samples were also constrained to $<2.25 \mathrm{~m}$ from plot fences, since interior samples could not be any farther than that distance from a fence. Numbers of seedlings inside the 4 samples within each plot were summed to yield seedling density (seedlings $\cdot \mathrm{m}^{-2}$ ), as were the 4 seedling count samples outside each plot.

I compared counts of quadrats containing S. paulsenii seedlings in rodent-access plots versus no-rodent plots by using $t$ tests for the difference between 2 means. If seed predation by rodents reduced S. paulsenii seed banks, I expected rodent-access plots to have lower counts of seedlings than no-rodent plots. Secondly, I compared the density of S. paulsenii seedlings within sampling frames inside versus outside no-rodent plots using a $t$ test for paired comparisons, and did the same analysis to compare densities inside versus outside rodent-access plots. If rodents reduced the seed bank, I expected the former analysis to reveal significantly lower seedling densities outside versus inside plots, but no such difference between outside and inside in the analy$s i s$ of rodent-access plots. Finally, I used $t$ tests for the difference between 2 means to compare seedling densities inside all rodent-access plots versus inside all no-rodent plots, and also to compare seedling densities outside rodent-access plots versus outside no-rodent plots. If rodents impact seedling densities, the former analysis should show lower seedling densities inside rodent-access plots compared with no-rodent plots, but the latter analysis should show no such differences, because the areas outside all plots are equally accessible to rodents.

For all of the above tests that compare means, I tested for homogeneity of variances between the 2 samples using $F_{\max }$ tests. All these tests revealed that variances of the 2 samples being compared were not significantly heterogeneous $(P>0.05)$, with 1 exception: in the 2005 data, variances differed significantly in a linear comparison of numbers of $S$. paulsenii seedlings in sampling frames inside no-rodent versus rodent-access plots $\left(F_{\max }=\right.$
4.43, $P<0.05)$. I used log-transformed data in the latter test to make the sample variances statistically similar $\left(F_{\max }=1.15, P>>0.05\right)$. Because densities of $S$. paulsenii seedlings can show extreme temporal variation, I analyzed 2004 and 2005 data separately. It should be noted that all of the above analyses that predict an effect on seed banks are 1-tailed tests, because they all predict the same direction of the effect (i.e., that rodent access should reduce seed banks). Although the analyses that do not predict an effect on seed banks are actually 2 tailed tests, I also applied 1-tailed $P$-values to these tests to make them directly comparable to analyses with a predicted effect. This approach reduces the chance of spuriously obtaining both significance for a predicted effect and nonsignificance for a corresponding test without a predicted direction of effect.

\section{RESULTS}

Up to 12 rodent-access plots and 14 norodent plots were available for use in each analysis. The number of plots included in analyses varied between tests and years because of, for example, degradation and maintenance of plot fences or because of sand having been blown out from buried fences on rodentaccess plots. In the latter case, the plots could be used for inside versus outside comparisons of density, but could not be used to compare counts of quadrats containing seedlings along fences, because the fence no longer constituted an effective windbreak for seeds.

The frequency of $S$. paulsenii seedlings along fences was significantly reduced inside rodent-access plots compared with no-rodent plots in both years of the study (Fig. 1; 2004: $t=3.36, \mathrm{df}=23$, 1-tailed $P<0.01 ; 2005: t=$ 3.91, df $=24,1$-tailed $P<<0.01$ ). No-rodent plots also had significantly lower seedling densities outside versus inside plots (Fig. 2; 2004: paired-sample $t=2.15$, $\mathrm{df}=12, P<0.03$; 2005: paired-sample $t=4.01, \mathrm{df}=12, P<$ $0.01)$. However, there were no such differences in S. paulsenii seedling density outside versus inside rodent-access plots (Fig. 2; 2004: paired-sample $t=1.48, \mathrm{df}=10, P>0.08$; 2005: paired-sample $t=0.42, \mathrm{df}=11, P>$ 0.33). Seedling densities were statistically similar outside rodent-access plots compared with outside no-rodent plots in both years of the study (2004: $t=1.50, \mathrm{df}=22, P>0.05 ; 2005$ : 

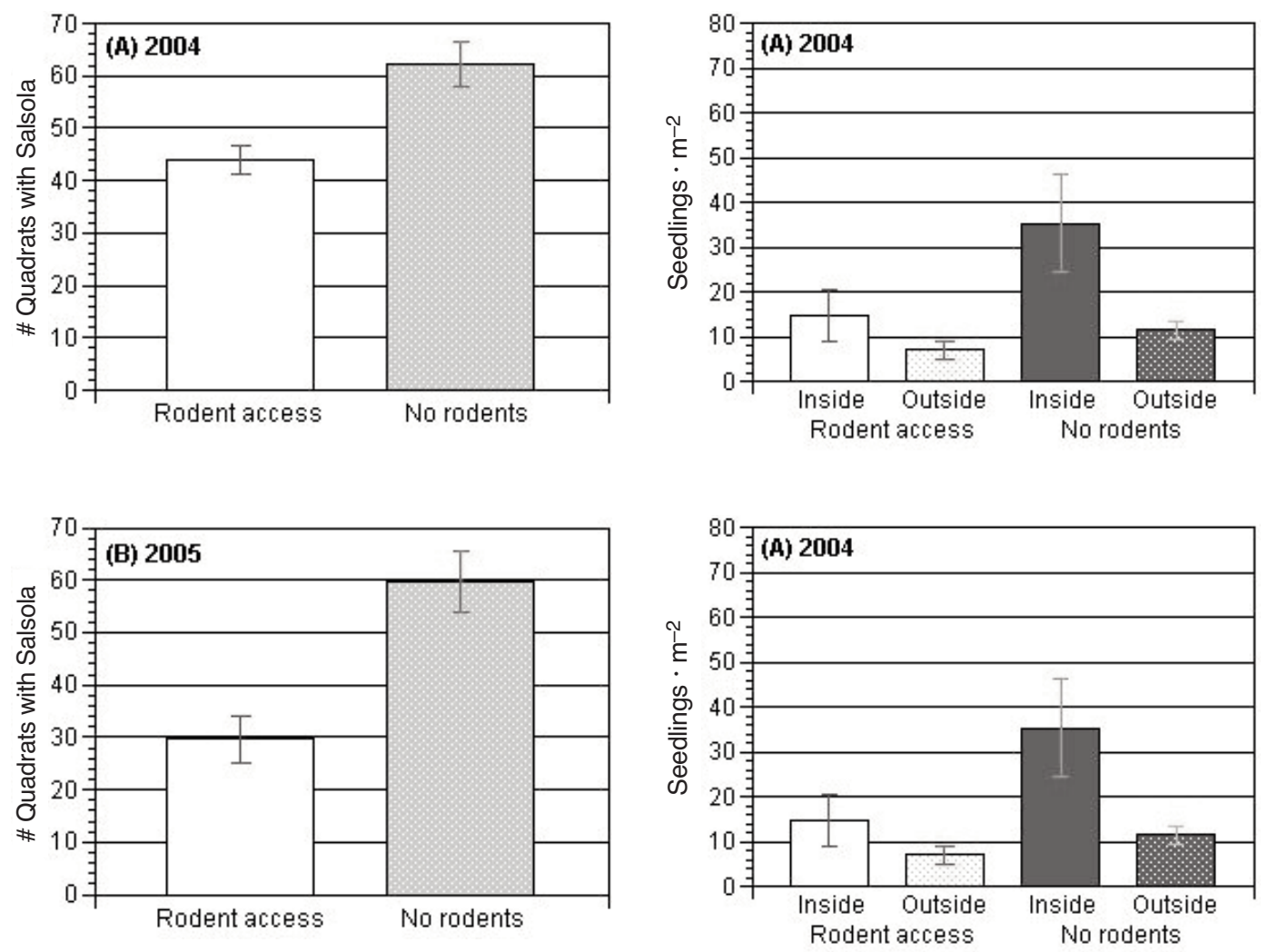

Fig. 1. Mean frequency counts $\left( \pm 1 s_{\bar{x}}\right)$ of Salsola paulsenii seedlings within contiguous $20 \times 20$-cm quadrats around interior edges of plots permitting rodent access versus plots with no rodents during 2004 (A) and 2005 (B).

$t=0.98, \mathrm{df}=22, P>0.10)$. Inside plots, $S$. paulsenii seedling densities were significantly reduced on rodent-access plots compared with no-rodent plots in 2005 ( $t$ test on log-transformed data: $t=5.27, \mathrm{df}=23, P<<0.01$ ), but there were no such density differences inside the 2 plot types in $2004(t=1.59$, df $=$ $23, P>0.05)$. With the single exception of the latter test, all of these results are consistent with the prediction that rodents reduce soil seed banks and subsequent seedling emergence of S. paulsenii.

\section{Discussion}

Postdispersal seed predation by desert rodents at the Hot Springs Mountains had a measurable effect over 2 consecutive years in reducing soil seed banks and subsequent seedling emergence of Salsola paulsenii. This effect was apparent in measures of seedling frequency inside rodent-access versus no-

Fig. 2. Mean density $\left( \pm 1 s_{\bar{x}}\right)$ of Salsola paulsenii seedlings inside versus outside fenced plots permitting rodent access versus plots with no rodents during 2004 (A) and 2005 (B).

rodent plots, and in measures of seedling density inside versus outside plots. Heteromyid rodents are likely the primary agents of this seed predation, because species of this family comprise the majority of the rodent community at the Hot Springs Mountains (Longland et al. 2001). I saw no indications of herbivory on seedlings during sampling, and plot openings did not permit access to black-tailed jackrabbits (Lepus californicus), the only mammalian herbivore at the site other than rodents. Therefore, herbivory by jackrabbits cannot explain the greater number of seedlings in norodent as compared with rodent-access plots. Although harvester ants (Pogonomyrmex salinus) are common at the study site and granivorous birds occur infrequently, the plots (some of which formerly excluded ants; Longland et al. 2001) were all equally accessible to these granivores in this study. Consequently, seed predation by nonrodent granivores cannot account for differences in the expression of 
S. paulsenii seedlings between different types of plots or between the inside and outside of plots.

Desert rodents have been shown in previous studies to harvest major proportions of seeds produced by various plants, including both native and introduced species. For example, Soholt (1973) estimated that rodents harvested $\sim 95 \%$ of seeds produced by the exotic annual Erodium cicutarium at a Mojave Desert site; and Chew and Chew (1970) estimated that rodents harvested $87 \%$ of seeds from a dominant native shrub (Larrea tridentata) at a Chihuahuan Desert site. In an old-field system in Ontario, Canada, Blaney and Kotanen (2001) experimentally measured seed removal for a large number of plant species and found that there were no systematic differences between native and exotic plants in levels of seeds taken by rodents. However, even if levels of seeds harvested are similar, interactions between rodents and seeds may have very different ultimate effects on native plants than on introduced plants. Granivorous rodents cache seeds as well as consume them, and at least some native plants have capitalized on this by utilizing the caching behavior of rodents as a seed dispersal mechanism (Vander Wall 1990).

The same fenced plots that I used in this study to demonstrate effects of rodents in reducing the S. paulsenii seed bank were used in a previous study of rodent-seed interactions involving a native perennial grass, Indian ricegrass (Achnatherum hymenoides; Longland et al. 2001). Although rodents also harvest a major portion of the annual seed crop of $A$. hymenoides, the ultimate effect of this seed use on plant fitness is probably very different for this species compared with S. paulsenii. For A. hymenoides, most seedling recruitment occurs from scatterhoard caches made by rodents (McAdoo et al. 1983, Longland et al. 2001), and seedling survival is enhanced (up to a certain seedling density) when seedlings of this plant emerge from caches in clumps (McMurray et al. 1997). By contrast, McMurray et al. (1997) showed that competition within clumps arising from rodent caches reduced seedling survival in an introduced, invasive annual grass species, cheatgrass (Bromus tectorum). Similarly, though large quantities of $S$. paulsenii seeds are harvested by desert rodents (McAdoo et al. 1983) and though seedlings often emerge from rodent scatterhoards at the
Hot Springs Mountains, these seedlings invariably die before maturing (Longland unpublished data, based on following the fates of hundreds of such seedling clumps over several years).

Though the above examples are too few to constitute robust evidence that native plants are more likely than introduced weeds to enjoy direct mutualistic relationships with granivorous rodents, one might expect this to be the case, because exotics do not share an evolutionary history with local granivores (Vander Wall 1990, Longland et al. 2001). Schiffman (1994) showed that densities of several introduced annual plants were enhanced in the immediate area around the burrows of the giant kangaroo rat (Dipodomys ingens) and argued that this constituted a plant-animal mutualism, but did not experimentally test effects of rodent exclusion on densities of these plants. Although Schiffman (1994, 1997) suggested that both soil disturbance and seed caching by rodents facilitated the higher densities of introduced plants near burrows, there was no mention of these seedlings emerging in clusters, as is characteristic of seedling recruitment from scatterhoards. Moreover, 1 of the 2 introduced species that showed the greatest increase around kangaroo rat burrows was Bromus madritensis ssp. rubens, a congener of B. tectorum, the species which McMurray et al. (1997) showed experimentally to suffer reduced fitness when seedlings emerged from caches. If a greater density of introduced plants in the vicinity of high rodent activity does constitute a mutualistic interaction, it is probably best characterized as an indirect or diffuse mutualism, rather than a coevolved, species-specific mutualism.

Although rodents reduced the S. paulsenii seed bank, this invasive weed still occurs conspicuously at the Hot Springs site. One can often witness noticeably higher densities of $S$. paulsenii inside compared with outside norodent plots, but the plant is still quite common over the local landscape, so there is little evidence for recruitment limitation. Similarly, some weeds continue to be problematic in agroecosystems despite measurable seed predation by rodents (Getz and Brighty 1986, Harrison et al. 2003, Westerman et al. 2003). In such cases, although seed predation by rodents may not bring weeds under effective control, it may well be that the weeds would 
occur in even greater densities without the impact of granivorous rodents in reducing their seed banks. In at least some systems, then, it is quite feasible that seed predation by native rodents may ameliorate competitive effects of invasive weeds on both agronomic crops and native range plants.

\section{ACKNOWLEDGMENTS}

I thank R. Ardelean and A. Murray for their assistance with data collection in the field. A. Murray and J. Young reviewed a preliminary draft of the manuscript and provided helpful suggestions for revision. This study is a contribution of the USDA Agricultural Research Service, Exotic and Invasive Weeds Research Unit, Reno, Nevada.

\section{Literature Cited}

BEATLEy, J.C. 1973. Russian thistle (Salsola) species in the western United States. Journal of Range Management 26:225-226.

Blaney, C.S., and P.M. Kotanen. 2001. Post-dispersal losses to seed predators: an experimental comparison of native and exotic old field plants. Canadian Journal of Botany 79:284-292.

Brown, J.H., And E.J. Heske. 1990. Control of a desertgrassland transition by a keystone rodent guild. Science 250:1705-1707.

Chew, R.M., And A.E. Chew. 1970. Energy relationships of the mammals of a desert shrub (Larrea tridentata) community. Ecological Monographs 40:1-21.

Evans, R.A., AND J.A. YounG. 1980. Establishment of barbwire Russian thistle (Salsola paulsenii) in desert environments. Journal of Range Management 33: 169-173.

Getz, L.L., And E. Brighty. 1986. Potential effects of small mammals in high-intensity agricultural systems in east-central Illinois. Agriculture, Ecosystems, and Environment 15:39-50.

Harrison, K.S., E.E. Regnier, and J.T. Schmoll. 2003. Postdispersal predation of giant ragweed (Ambrosia trifida) seed in no-tillage corn. Weed Science 51: 955-964.

Hulme, P.E. 1998. Post-dispersal seed predation: consequences for plant demography and evolution. Perspectives in Plant Ecology, Evolution and Systematics 1:32-46.

JACOBS, L.F. 1992. Memory for cache locations in Merriam's kangaroo rats. Animal Behaviour 43:585-593.

Johnson, T.K., And C.D. Jorgensen. 1981. Ability of desert rodents to find buried seeds. Journal of Range Management 34:312-314.

LONGLAND, W.S. 1994. Seed use by desert granivores. Pages 233-237 in S.B. Monson and S.G. Kitchen, editors, Proceedings of the symposium on ecology, management, and restoration of Intermountain annual rangelands. USDA Forest Service INT-GTR-313.
Longland, W.S., S.H. Jenkins, S.B. Vander Wall, J.A. VEECH, AND S. PYARE. 2001. Seedling recruitment in Oryzopsis hymenoides: are desert granivores mutualists or predators? Ecology 82:3131-3148.

McAdoo, J.K., C.C. Evans, B.A. Roundy, J.A. Young, And R.A. Evans. 1983. Influence of heteromyid rodents on Oryzopis hymenoides germination. Journal of Range Management 36:61-64.

McMurray, M.H., S.H. Jenkins, and W.S. Longland. 1997. Effects of seed density on germination and establishment of a native and an introduced grass species dispersed by granivorous rodents. American Midland Naturalist 138:322-330.

Price, M.V., AND K.M. Heinz. 1984. Effects of body size, seed density, and soil characteristics of rates of seed harvest by heteromyid rodents. Oecologia 61:420-425.

Price, M.V., and S.H. Jenkins. 1986. Rodents as seed consumers and dispersers. Pages 191-235 in D.R. Murray, editor, Seed dispersal. Academic Press, Inc., San Diego, CA.

Reichman, O.J. 1979. Desert granivore foraging and its impact on seed densities and distributions. Ecology 60:1085-1092.

Schiffman, P.M. 1994. Promotion of exotic weed establishment by endangered giant kangaroo rats (Dipodomys ingens) in a California grassland. Biodiversity and Conservation 3:524-537.

1997. Animal-mediated dispersal and disturbance: driving forces behind alien plant naturalization. Pages 87-94 in J.O. Luken and J.W. Thieret, editors, Assessment and management of plant invasions. Springer-Verlag, New York.

Smith, L. 2005. Host plant specificity and potential impact of Aceria salsolae (Acari: Eriophyidae), an agent proposed for biological control of Russian thistle (Salsola tragus). Biological Control 34:83-92.

SoHolT, L.F. 1973. Consumption of primary production by a population of kangaroo rats (Dipodomys merriami) in the Mojave desert. Ecological Monographs 43:357-376.

VANDER WALL, S.B. 1990. Food hoarding in animals. University of Chicago Press, Chicago, IL.

Vander Wall, S.B., M.J. Beck, J.S. Briggs, J.K. Roth, T.C. Thayer, J.L. Hollander, and J.M. Armstrong. 2003. Interspecific variation in the olfactory abilities of granivorous rodents. Journal of Mammalogy 84: 487-496.

Vander Wall, S.B., W.S. Longland, S. Pyare, and J.A. VEECH. 1998. Cheek pouch capacities and loading rates of heteromyid rodents. Oecologia 113:21-28.

Westerman, P.R., A. Hofman, L.E.M. Vet, and W. van DER WERF. 2003. Relative importance of vertebrates and invertebrates in epigeaic weed seed predation in organic fields. Agriculture, Ecosystems, and Environment 95:417-425.

Young, J.A., And R.A. Evans. 1979. Barbwire Russian thistle (Salsola paulsenii) seed germination. Journal of Range Management 32:390-394.

Received 30 December 2005 Accepted 15 November 2006 